\title{
EVALUASI SISTEM MANAJEMEN MUTU INTERNAL DALAM LINGKUP PELAYANAN AKADEMIK DI UNIVERSITAS LAMPUNG
}

\author{
Dwi Ika Febriani*
}

\begin{abstract}
This research aims to determines compatibility of (1) quality planning, (2) quality improvement, (3) quality control, and (4) quality assurance at quality assurance program of higher education in University of Lampung. Evaluation approach used in this research is objective - oriented evaluation model, with qualitative evaluation method. This research is focus on congruence between the objective of the program and its actual outcomes. Evaluation results showed that implementation of quality assurance in University of Lampung has been implemented since 2001 till now has been running well. They implemented they own concept called Unilaway. But there are some problems must be resolved, so the implementation of quality assurance in University of Lampung would be better so that the purpose of the implementation quality assurance in University of Lampung immedietaly reached.
\end{abstract}

Keywords: Quality assurance, objective-oriented evaluation model, qualitative evaluation method.

\section{PENDAHULUAN}

Telah di ketahui bahwa penjaminan mutu di perguruan tinggi terdiri atas, penjaminan mutu internal, (Internal Quality Assurance) dan penjaminan mutu eksternal (External Quality Assurance). Integrasi tersebut membentuk suatu sistem yang komprehensif yaitu Sistem Penjaminan Mutu Perguruan Tinggi (SPM-PT). Sebagai salah satu sub sistem SPM-PT penjaminan mutu internal tersebut perlu dievaluasi implementasinya. Salah satu perguruan tinggi yang telah masuk jajaran sistem evaluasi implementasi sistem manajemen mutu internal tersebut adalah Universitas Lampung. Dalam evaluasi yang dilakukan oleh kelompok kerja depdiknas diketahui bahwa Universitas lampung mampu menduduki peringkat ke 44 . dengan peringkat tersebut terlihat bahwa sistem manajemen mutu di Universitas Lampung belum berjalan maksimal untuk mencapai peringkat teratas dalam penilaian kementerian dalam hal penjaminan mutu.

Dengan demikian diperlukan evaluasi implementasi terhadap program tersebut di civitas akademika Universitas Lampung. Selain itu juga harus dilakukan evaluasi berkala sehingga menunjang sistem terpadu yang terkait untuk menunjang pelayanan akademik yang baik di jajaran civitas akademika yang termasuk di dalamnya adalah mahasiswa dan dosen. Menyadari hal tersebut dan mengingat pentingnya penyelenggaraan yang berkualitas maka setiap Perguruan Tinggi berkewajiban memberikan pelayanan yang baik terhadap seluruh mahasiswanya sehingga dapat menghasilkan lulusan yang berkualitas dan mampu untuk bersaing di dunia kerja. Untuk itu diperlukan peningkatan pelayanan akademik yang progresif dan diharapkan setelah adanya penilaian evaluasi tersebut Universitas Lampung dapat meningkatkan Pelayanan Akademik yang optimal.

Berdasarkan uraian di atas untuk mencapai peningkatan sistem penjaminan mutu yang baik di Universitas Lampung diperlukan evaluasi implementasi sistem manajemen mutu internal agar diketahui kesesuaian antara standar yang telah dikembangakan Dikti dengan pengembangan yang dilakukan Universitas Lampung serta

\footnotetext{
*Asisten Dosen Universitas Negeri Lampung
} 
meningkatkan pelayanan akademik di lingkungan civitas akademika di Universitas Lampung. Maka dari itu penulis memberi judul penelitian ini " Evaluasi Sistem Manajemen Mutu Internal Untuk Meningkatkan Pelayanan Akademik di Universitas Lampung 2011".

\section{Evaluasi}

Evaluasi menurut Stake in Susan Harris - Huemert (2009:42) books, "evaluation as 'an observed value compared to some standard" evaluasi didefinisikan sebagai nilai yang diamati dan dibandingkan dengan standar tertentu. Dia mengemukakan titik yang valid, bahwa setiap evaluasi akan meninggalkan beberapa penekanan-penekanan sehingga tidak ada proses evaluasi yang dapat melakukan keadilan terhadap sesuatu hal yang diamati. Lalu Nigel Norris and Savville Kushner (2007:7-8) di bukunya menyatakan, "evaluation is a resources to be used to increase "intelligence" and "even up" the distribution of information". Evaluasi adalah sumber daya yang digunakan untuk meningkatkan kecerdasan dan meningkatkan pembagian informasi, selain itu juga evaluasi diyakini dapat meningkatkan atau mempromosikan kepercayaan. Guba \& Lincoln dalam Susan (2009:42) "defined evaluation as "the systematic investigation of an evaluand's worth or merit". Evaluasi didefinisikan sebagai penyelidikan sistematis dari penilaian prestasi.

Ralph Tyler (2008:3) menyatakan definisi evaluasi adalah proses yang menentukan sampai sejauh mana tujuan pendidikan dapat dicapai. Pendapat Ralph Tyler (2008:3) sering dijadikan referensi, beliau juga dinilai sebagai bapak evaluasi pendidikan. Konsep yang dikemukakan Tyler adalah perbandingan hasil yang ditujukan dengan hasil yang sebenarnya. Padangannya terhadap evaluasi memiliki keunggulan yang jelas dari pendekatan sebelumnya. Karena evaluasi Tylerian melibatkan perbandingan hasil dengan sasaran. Yang terbaru dikemukakan oleh Fournier beliau mendeskripsikan, "evaluation as an "applied inquiry process for collecting and synthesizing evidence that culminates in conclusions about the state of affairs, value, merit, worth, significance, or quality of a program, person, policy, proposal, and plan". Evaluasi merupakan proses penyelidikan yang diterapkan untuk mengumpulkan dan mensintesiskan bukti yang berujung kepada sebuah kesimpulan tentang keadaan, nilai, prestasi, makna atau kualitas sebuah program, kebijakan, proposal dan rencana. Definisi ini lebih disukai karena mengindikasikan keluasan dan komplesitas evaluasi dan tidak menutupi permasalahan yang sebenarnya.

Definisi evaluasi menurut Stufflebeam, Kellaghan, dan Madaus (2000:26) harus menjalankan keseluruhan sudut pandang dibawah ini :
a. Modernity to post - mordernity
b. Rationalistic to naturalistic
c. Elemenistic/reductionist to holistic
d. Meta-narratives to no such thing as meta narratives
e. Prediction to elimination
f. Knowing to feeling
g. Control to empowerment
$h$. Knowledge producing to experience producing
i. Evaluative inquiry to evaluative technology
j. Measurement quantification to qualitative description
k. Proof to persuasion
l. Evaluator makes judgement of merit or worth to client makes such judgement. 
Definisi di atas mengungkapkan serangkaian posisi estimologis, dan ideologis yang berada di antara teori pada sifat evaluasi, yaitu bagaimana melaksanakan evaluasi, bagaimana cara menyajikannya dan menggunakan hasil evaluasi tersebut. Tujuan pencapaian model evaluasi. Bahwa gagasan penilaian program atau seseorang harus di setarakan dengan pencapaian sukses pada tujuan yang telah ditetapkan. Dari uraian di atas, dapat disintesiskan evaluasi adalah proses yang sistematis untuk menilai kualitas atau mengartikan sesuatu dengan cara mengukur kualitas dengan standar yang telah ditentukan dalam rangka pengambilan keputusan.

\section{Model-model Evaluasi}

1. Objective-Oriented Evaluation Model. Objective - oriented evaluation model adalah model yang muncul paling awal. Yang menjadi objek pengamatan pada objek ini adalah tujuan dari program yang sudah ditetapkan jauh sebelum program dimulai. Evaluasi ini dilakukan secara berkesinambungan dan terus menerus, mencek seberapa jauh tujuan tersebut telah terlaksana didalam proses pelaksanaan program.

2. Evaluasi Model CIPP. Stufflebeam membuat pedoman kerja untuk melayani para manajer dan administrator menghadapi empat macam keputusan (Fitzpatrick, 2004:89) yaitu:context, input, process, product.

3. Evaluasi Model UCLA. Pada saat Alkin menjadi ketua pusat studi evaluasi di Univesitas California, (CSE-UCLA, Center for Study Evaluation University of California Los Angeles) beliau mengembangkan kerangka yang hampir sama aspeknya dengan CIPP model. Alkin mendefinisikan evaluasi sebagai suatu proses menyakinkan keputusan, memilih informasi yang tepat, mengumpulkan, dan menganalisis informasi sehingga dapat melaporkan ringkasan data yang berguna bagi pembuat keputusan dalam memilih beberapa alternatif.

4. Responsive Evaluation. Evaluasi responsif merupakan suatu proses pemerolehan informasi yang besifat pengulangan mengenai institusi, program atau proyek dengan mendefinisikan berbagai isu kepentingan pada para konstituen dan memaparkan kekuatan dan kendala yang menyangkut isu tersebut.

5. Countenance Evaluation Model. Model ini dikembangkan oleh Stake, model Stake menekankan pada adanya pelaksanaan dua hal pokok yaitu (1) deskripsi dan (2) pertimbangan, serta membedakan adanya tiga tahap dalam evaluasi program yaitu (1) Anteseden, (2) transaksi, (3) dan keluaran.

6. Goal-Free Evaluation. Model evaluasi yang dikembangkan oleh Michael Scriven ini dapat dikatakan berlawanan dengan model yang dikembangkan oleh Tyler. Jika dalam model yang dikembangkan, evaluator terus menerus memantau tujuan, yaitu sejak awal proses terus melihat sejauhmana tujuan tersebut sudah dapat dicapai, dalam model goal-free evaluation justru menoleh pada tujuan.

7. Discrepancy Model. Model ini dikembangkan oleh Michael Provus ini merupakan model yang menekankan pada pandangan adanya kesenjangan di dalam pelaksanaan program. Evaluasi program yang dilakukan oleh evaluator mengukur besarnya kesenjangan yang ada dalam setiap komponen.

\section{Sistem Manajemen Mutu Internal di Perguruan Tinggi}

Upaya peningkatan mutu perguruan tinggi terus menerus dilakukan, salah satu upaya adalah mengembangkan penjaminan mutu di perguruan tinggi. Pada tanggal 16 mei 2005 ditetapkan peraturan pemerintah (PP) No. 19 tahun 2005 tentang standar nasional pendidikan (SNP). Di dalam pasal 4 Peraturan Pemerintah tersebut dijelaskan bahwa SNP bertujuan menjamin mutu pendidikan nasional. Oleh karena itu, 
pemenuhan SNP oleh suatu perguruan tinggi berarti bahwa perguruan tinggi tersebut menjamin mutu pendidikan tinggi yang diselenggarakannya. Maka SNP dapat disebut pula sebagai standar mutu pendidikan tinggi di Indonesia yang harus dipenuhi oleh seluruh perguruan tinggi. Keberadaan lembaga penjamin mutu di perguruan tinggi merupakan sebuah keharusan sebagai upaya setiap perguruan tinggi memberikan jaminan mutu proses dan hasil pendidikan kepada stakeholders baik internal maupun eksternal. Sebagai tindak lanjut untuk mencapai hal tersebut di beberapa perguruan tinggi mengawalinya dengan pembentukan lembaga, badan, kantor, unit, satuan, penjaminan perguruan tinggi atau Quality Assurance (QA) termasuk Universitas Lampung.

\section{Konsep Mutu Trilogy Juran}

Untuk memahami berbagai persoalan tentang sistem manajemen penjaminan mutu pendidikan tinggi perlu dipahami terlebih dahulu konsep mutu dan pengertian penjaminan mutu serta sistem manajemen mutu perguruan tinggi tersebut. Kualitas merupakan hal yang sering diperdebatkan panjang, untuk beberapa orang hal tersebut diartikan sebagai keindahan bagi orang yang melihatnya. Mereka yang menyakini ini, merupakan kaum relativis. Sedangkan mereka yang percaya kualitas dapat menjadi atribut khusus yang dapat diidentifikasikan, mereka adalah para objektif. Kata kualitas berasal dari bahasa latin quails yang berarti 'seperti apa'. Dengan beragam makna dan konotasi hal tersebut diasumsikan sebagai Slippery concept.

\section{Dasar Hukum Penjaminan Mutu Pendidikan Tinggi}

Penjaminan mutu pendidikan di perguruan tinggi adalah proses penetapan dan pemenuhan standar mutu pengelolaan pendidikan tinggi secara konsisten dan berkelanjutan, sehingga stakeholders (mahasiswa, orang tua, dunia kerja, pemerintah, dosen, tenaga penunjang, serta pihak lain yang berkepentingan) memperoleh kepuasan, seperti yang dikatakan oleh Ponpon dengan mengatakan bahwa : Salah satu strategic issues di dalam HELTS 2003- 2010 adalah E. Point Quality Assurance atau penjaminan mutu sebagai berikut, "in healthy organization, a continuous quality improvement should become its primary concern. Quality assurance should be internally driven, institutionalized within each organization's standard procedure, and could also involve external parties. However since quality is also concern of all stakeholders, quality improvement should aim at producing quality outputs and outcomes as part of public accountability". Tuntutan perguruan tinggi untuk memiliki organisasi yang sehat merupakan salah satu strategi point dalam HELTS, 2003-2010 dimana "a continuous quality improvement should become its primary concern". Hanya organisasi atau satuan pendidikan yang sehatlah yang dapat memberikan pelayanan yang baik bagi terjadinya "a continuous quality improvement".

\section{METODE}

Penelitian evaluasi ini dilaksanakan di Universitas Lampung, Peneliti akan mengambil data dengan melakukan wawancara terhadap beberapa sumber data. Model dan pendekatan evaluasi yang dipakai dalam penelitian ini adalah model objectivesoriented evaluation model. Adapun metode penelitian yang digunakan dalam penelitian ini adalah evaluasi kualitatif. Desain penelitian yang akan digunakan adalah menyesuaikan tujuan dan hasil tujuan dengan standar tertentu yang kemudian hasilnya akan di justifikasi apakah tujuan program atau sistem telah tercapai atau belum, dan 
selanjutnya hasil dari peneltian ini akan diakhiri dengan rekomendasi. Instrument yang digunakan dalam penelitian evaluasi meliputi: pedoman wawancara, angket, dan pedoman observasi.

\section{HASIL DAN PEMBAHASAN}

\section{Pembahasan Perencanaan Mutu (Quality Planning)}

Secara menyeluruh dalam perencanaan mutu di Universitas lampung telah melakukan rancangan tersendiri untuk memudahkan memasukan sistem penerapan penjaminan mutu secara baik dan benar. Terbukti dengan dibuat inovasi tersendiri yang dinamakan unilaway, pengelola membuat se efisien mungkin rancangan tersebut untuk diterapkan kepada masing-masing fakultas, jurusan dan program studi.

Tujuan penerapan penjaminan mutu di Universitas Lampung dengan jelas dan tegas menyatakan agar unila dapat bersaing dan menjadi benchmarking antara universitas-universitas di Indonesia. Untuk penentuan kebutuhan kebutuhan stakeholders internal pengelola kurang secara rinci menjelaskan dan mengadakan temu pendapat antara mahasiswa dan dosen dalam penentuan kebutuhan yang sebenarnya. Terbukti bahwa kebutuhan yang disebutkan oleh pengelola penerapan hanya sebatas kepastian informasi. Dalam sebar kuisioner yang dilakukan peneliti dalam pertanyaan identifikasi kebutuhan mahasiswa sebagian besar informan yang ditemui peneliti mengatakan bahwa fasilitas merupakan hal utama yang harus dipenuhi oleh kampus untuk menunjang pembelajaran yang baik di kelas. Dalam sebaran kuisioner yang dilakukan penulis kepada beberapa mahasiswa dari berbagai fakultas menyatakan $20 \%$ menyatakan fasilitas di Unila telah cukup memadai, sedangkan yang menjawab raguragu sekitar 30\% lalu 50\% mahasiswa menjawab bahwa fasilitas di Unila belum mencukupi dalam menunjang pembalajaran.

Dalam pengembangan inovasi Universitas Lampung dapat dikatakan telah mengeluarkan dan menciptakan ide-ide yang baik dalam melakukan penjaminan mutu di unila, dengan diciptakannya unilaway serta inovasi penjaminan mutu laboratorium diharapakan sistem tersebut dapat berjalan dengan baik sehingga dapat menunjang percepatan mutu yang meningkat. Hambatan-hambatan yang ditemui ketika penerapan inovasi tersebut telah dilalui dengan baik namun hambatan utama adalah data yang telah diperoleh Universitas Lampung ketika mengelola penjaminan mutu belum sepenuhnya dipakai pimpinan untuk mengambil keputusan untuk memajukan mutu universitas. Sehingga pengembangan inovasi tersebut terkesan jalan di tempat.

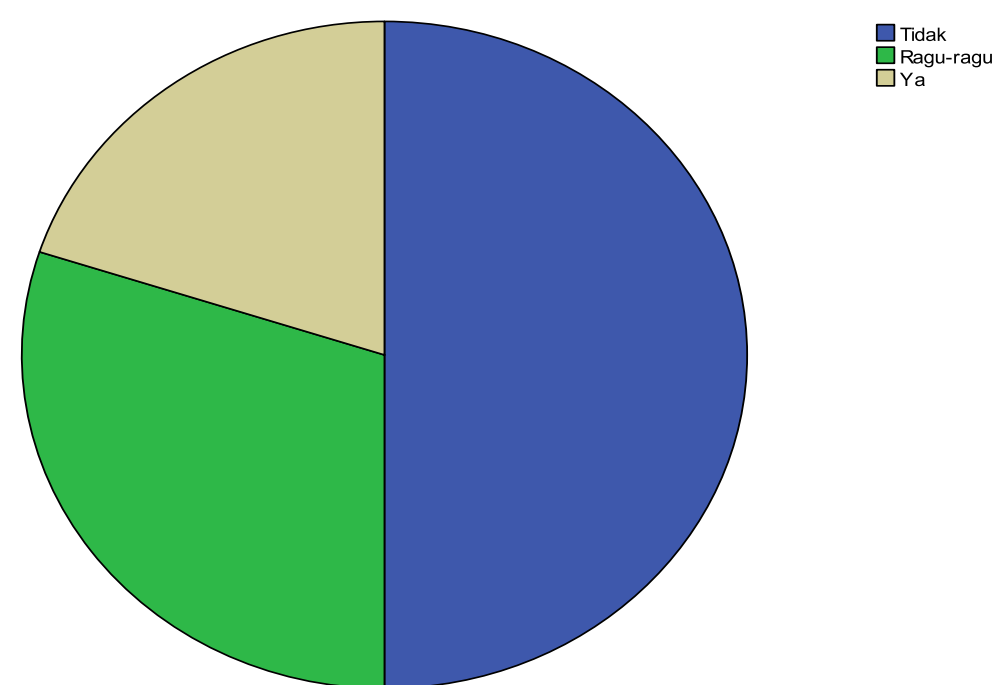




\section{Gambar. 1 hasil pie chart terhadap kepuasan mahasiswa tentang fasilitas dan peralatan}

Bagan di atas menunjukan bahwa kepuasan mahasiswa terhadap fasilitas di Universitas Lampung belum mencukupi. Dalam hasil analisis angket yang dilakukan peneliti sebanyak 50\% Responden menjawab fasilitas di Universitas Lampung belum mencukupi kebutuhan mahasiswa, lalu 30\% responden menjawab ragu-ragu, dan 20\% menjawab kebutuhan fasilitas di Unila telah mencukupi.

\section{Pembahasan Perbaikan Mutu (Quality Improvement)}

Dalam perbaikan mutu di Universitas Lampung telah melakukan berbagai perbaikan mutu program sebelumnya, serta membangun beberapa infrastruktur untuk kelancaran kinerja pengelolaan manajemen mutu internal di Universitas Lampung. Namun perbaikan program dan pembangunan infrastruktur tersebut belum berjalan maksimal. seperti pembuktian kebutuhan stakeholders pengelola mengakui tidak dilakukannya survey langsung untuk membuktikan kebutuhan stakeholders. Sehingga tidak bisa dibuktikan langsung apa yang benar-benar dibutuhkan oleh stakeholders. Pengelola penjamin mutu hanya mengglobalkan kebutuhan tersebut hanya kepada kebutuhan dan ketepatan informasi. Infrastruktur yang dikhususkan untuk penyelenggaraan manajemen mutu internal tidak dijalankan. Karena berawal dari ketidak

dukungan yang dilakukan pemimpin dan civitas terhadap lembaga penjamin mutu, untuk pembangunan infrastruktur khusus belum bisa di realisasikan. Karena dalam membangun infrastruktur khusus diperlukan dana yang besar dan tentu saja dukungan dari berbagai pihak. Namun untuk penyelenggaraan ketepatan informasi seperti kemudahan akses nilai serta informasi-informasi khusus lainnya, PPMU bekerja sama dengan pusat komputer.

Pusat komputer sebagai penyedia komputer bagi mahasiswa serta mengelola internet seluruh civitas dan memanage sistem informasi bagi mahasiswa, dosen, staf serta masyarakat luas. Tim kerja dalam melakukan sistem manajemen mutu internal memang telah dilakukan pengelola, namun tidak ada tim kerja khusus yang dibawahi oleh PPMU untuk mnegelola di fakultas langsung, tim manajemen mutu fakultas hanya tim yang di usulkan oleh fakultas. Tim kerja manajemen mutu di fakultas tidak diberi pelatihan-pelatihan khusus dan pengetahuan khusus tentang manajemen mutu. Tim kerja fakultas hanya memonitori dan mensosialisasi ketika diadakan evaluasi serta monitoring di fakultas. Tidak ada pedoman dan kriteria khusus dalam membangun tim kerja manajemen mutu di fakultas dan program studi. Kendala yang terlihat dalam membangun tim kerja adalah tim kerja tersebut tidak mempunyai keahlian khusus, serta masih bergantung terhadap fakultas. Tidak ada tim kerja khusus dengan keahlian khusus dalam manajamenkan mutu di fakultas, dalam pelaksanaan manajemen mutu 
internal di perguruan tinggi unila telah mengadakan beberapa pelatihan yang diselenggarakan oleh PPMU. Baik itu pelatihan apa itu sistem manajemen mutu, serta bagaimana pengisisan borang dan dokumen yang dibutuhkan dalam monitoring dan evaluasi. Selain diadakan pelatihan diadakan juga lokakarya yang bekerja sama dengan (I-MHERE) untuk improving quality assurance. Lokakarya tersebut dimaksudkan untuk memperbaiki sistem manajemen mutu yang dilakukan oleh universitas lampung. Dengan bekerja sama dengan I-MHERE lokarya tersebut diharapkan dapat meningkatkan pelaksanaan manajemen mutu di Univeritas Lampung.

Untuk penetapan kontrol pengelola tidak mengadakan pengontrolan secara khusus dan berkala, kontrol terhadap kinerja fakultas hanya dilihat dari pengisian borang monitoring dan evaluasi. Pengelola hanya menonitoring kinerja tiap fakultas dan program studi.

\section{Pembahasan Kontrol Mutu (Quality Control)}

Evaluasi terhadap lembaga selalu dilakukan secara berkala oleh Universitas Lampung dan penilaian kinerja tersebut telah dilalukan publikasi, baik di masingmasing fakultas, melalui situs Unila maupun ketika rapat-rapat yang dilakukan oleh tim penjamin mutu. Tahun ini PPMU telah melakukan RTM keseluruhan di mana pada awalanya dilakukan RTM di jurusan dan program studi. RTM ini bertujuan untuk meninjau manajemen yang diberlakukan oleh jurusan dan program studi. Dilihat apakah manajemen yang distandarkan oleh program studi dan jurusan sudah mewakili standar mutu yang diberlakukan oleh universitas.

Dengan adanya penilaian dan evaluasi kinerja per fakultas, universitas dapat memonitoring dan memperbaiki kinerja-kinerja seluruh universitasnya, sehingga kemajuan mutu yang diharapkan dapat segera terwujud. Dengan adanya penilaian tersebut, Unila dapat melihat secara langsung mana fakultas yang memerlukan treatment khusus untuk menaikan kinerja agar dapat meningkatkan mutu fakultas lebih baik lagi. Begitu juga kinerja jurusan, data-data ini sangat membantu kerja universitas agar dapat memfokuskan diri dalam menaikan kinerja jurusan dan fakultas secara baik.

Pada tanggal 15 November 2011, diadakan rapat tinjauan manajemen Universitas Lampung yang dihadiri langsung oleh rektor dan diharapkan kegiatan perkegiatan

menajemen mutu di Universitas Lampung mendapat dukungan sepenuhnya dari tingkat pimpinan. RTM ini bertujuan menjelaskan beberapa data kinerja seluruh fakultas, jurusan dan program studi sampai kinerja lembaga di Universitas Lampung.

Dengan adanya data yang jelas, PPMU dapat membandingkan seluruh kinerja lembaga baik fakultas maupun jurusan dan program studi. Dari situ dapat dilakukan perbandingan pada setiap tingkatan lembaga, fakultas satu dengan fakultas lainnya, lalu antar jurusan, antar program studi serta antar kinerja lab. Sehingga akan di hasilkan tingkat persaingan tim terbaik untuk menghasilkan atmosfir persaingan secara sehat. Masing-masing fakultas dan jurusan diharapkan berlomba meningkatkan kinerja mutu masing-masing sehingga budaya untuk meningkatkan mutu pada masing-masing lembaga didapat secara maksimal.

Perbedaan dalam setiap fakultas di Universitas Lampung sudah pasti ada, di mana setiap fakultas mempunyai cara tersendiri dalam menangani setiap permasalahan fakultas. sudah pasti fakultas hukum akan berbeda budaya dengan fakultas teknik dan sebagainya. Perbedaan tersebut bukanlah kendala. Dalam penerapan SPMI di fakultas terdapat tim kerja fakultas yang memahami budaya di fakultas masing-masing sehingga penerapan SPMI di fakultas dapat di laksanakan dengan baik. Di buat cara khusus 
sesuai dengan buaya di fakultas masing-masing sehingga penerapan SPMI di fakultas dapat berjalan maksimal.

\section{Pembahasan Penjaminan Mutu (Quality Assurance)}

Program telah dijalankan oleh PPMU serta telah dilakukan evaluasi secara berkala. Seperti halnya program-program lain kendala yang dihadapi adalah tim di fakultas tidak menjalankan tugas dengan baik, karena mereka masih berfikir bahwa melakukan penjaminan mutu hanya menghabiskan waktu saja sedangkan kegiatan yang lain masih banyak dijalankan. Sehingga PPMU harus bisa membuktikan bahwa penjaminan mutu penting untuk dijalankan.

Dalam memonitoring dan mengontrol program PPMU melakukan monitoring secara online sehingga dapat memudahkan mobilitas baik dari fakultas maupun PPMU sendiri. Memang ada beberapa kelemahan yang dialami ketika melakukan monitoring online karena PPMU tidak mengetahui secara langsung apakah progam telah berjalan dengan baik atau belum sehingga diharapkan akan ada monitoring langsung sehingga mengetahui secara pasti apakah program telah berjalan dengan baik. Setahun sekali secara berkala memang telah dilakukan inspeksi terhadap fakultas-fakultas, inspeksi tersebut untuk melihat bagaimana kinerja fakultas dalam menjalankan program manajemen mutu. Namun sambutan dalam inspeksi tersebut memang belum maksimal dikarenakan kurangnya kesadaran terhadap pentingnya manajemen mutu untuk meningkarkan mutu fakultas masing-masing.

Hasil yang optimal memang belum dirasakan banyak ketika peneliti menyebarkan survey langsung apa kebutuhan utama dari stakeholders itu sendiri. Pihak PPMU mengklaim bahwa kebutuhan informasi yang tepat adalah kebutuhan utama saat ini. Dan mereka menilai bahwa kebutuhan-kebutuhan yang lain sudah dirangkum ketika mereka mencapai siklus ke-7, namun data-data tersebut tidak ditindak lanjuti oleh pimpinan sehingga dirasakan peningkatan mutu di Unila seperti jalan di tempat. Namun untuk

peningkatan layanan dan kinerja PPMU telah mengklaim sudah dirasakan cukup baik, di mana grade yang telah di peroleh fakultas sudah mencapai grade B. dan beberapa fakultas dan jurusan telah mencapai akreditasi A. Kepuasan pelanggan sendiri, mahasiswa masih memberi nilai rata-rata. Bisa dinilai bahwa peningkatan mutu di Unila masih jalan di tempat.

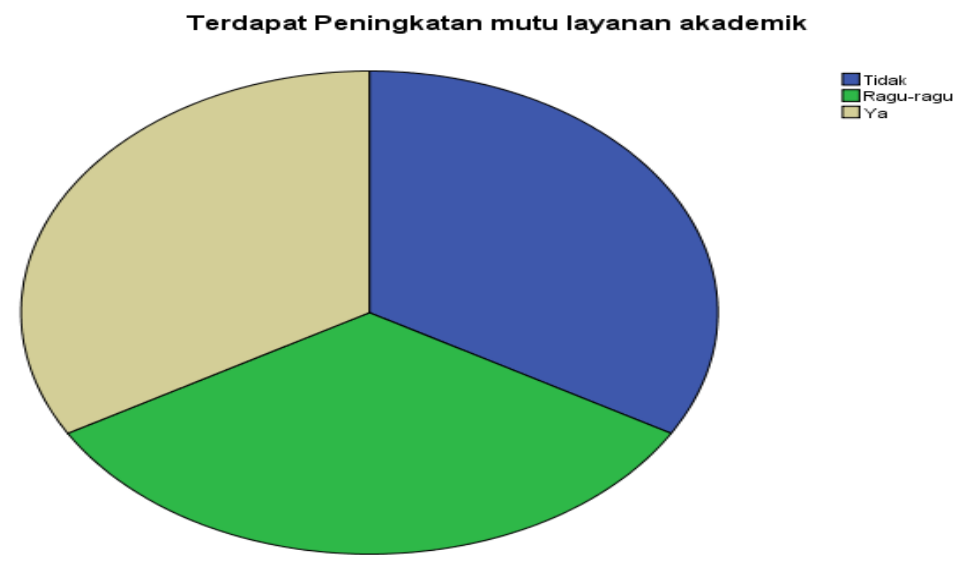




\section{Gambar. 2. Hasil survey terhadap Peningkatan Mutu layanan akademik di Unila.}

Bagan di atas merupakan survey yang dilakukan penulis terhadap pertanyaan "apakah terdapat peningkatan mutu pelayanan akademik di Unila" dan hasil dari survey tersebut adalah rata-rata di mana responden menunjukan hasil 33.3\% terhadap semua jawaban. Yang berarti belum ada peningkatan mutu pelayanan akademik di Unila sampai saat ini.

\section{PENUTUP}

Kesimpulan. Berdasarkan hasil evaluasi yang dilakukan peneliti tujuan yang telah di rancang di awal program telah tercapai, walupun belum sepenuhnya. 1) Terdapat beberapa kendala yang harus diatasi untuk mencapai tujuan tersebut. Pengelola dan lembaga belum melakukan pengidentifikasian kebutuhan secara menyeluruh, sehingga rinci dari kebutuhan stakeholders belum terpenuhi dengan baik. 2) Unila tidak melakukan survey kebutuhan secara langsung, sehingga apa yang benar-benar dibutuhkan stakeholder tidak diketahui jelas oleh lembaga dan pengelola manajemen mutu, sehingga kebutuhan pokok dari mahasiswa tidak terpenuhi. Untuk infrastruktur penunjang sistem manajemen mutu sudah terdapat alat-alat penunjang sistem penerapan SPMI walaupun belum tercukupi maksimal. Pada hasil penelitian tentang adanya evaluasi kinerja di Unila sudah terdapat evaluasi kinerja yang dilakukan oleh lembaga dengan baik. Hasil penelitian menunjukan terdapat evaluasi program untuk menilai apakah program yang dijalankan telah berjalan dengan baik, kendala utama dalam setiap evaluasi adalah kurangnya perhatian dari pimpinan.

Rekomendasi. Berdasarkan kesimpulan di atas, maka beberapa rekomendasi yang diajukan antara lain: 1) Diharapkan peran pimpinan dalam mengatasi kendala-kendala yang dihadapi oleh tim penjamin mutu. Terjadi kerja sama dalam meningkatkan mutu universitas secara menyeluruh. Sosialisasi diharapkan terus digalakan, serta sosialisasi kesadaran akan pentingnya jaminan mutu untuk seluruh civitas. 2) Dilakukan pengidentifikasian dan survey kebutuhan dari mahasiswa dan dosen, sehingga dengan mengetahui kebutuhan tersebut dapat mempermudah jalannya program penerapan manajemen mutu internal. 3) Pengelola atau PPMU selalu mencari inovasi terbaru untuk mempermudah program penjaminan mutu masuk ke dalam fakultas-fakultas, mempermudah jalan penilaian sehingga tidak membuat persepsi bahwa penjaminan mutu "hanya menambah pekerjaan saja". 4) Diadakan monitoring dan kontrol secara menyeluruh dan berkala, sehingga diketahui apakah program berjalan dengan baik atau tidak. 5) Ditindaklanjutinya data-data yang diperoleh oleh tim manajemen mutu yang telah memperoleh data sampai siklus ke-7, data-data tersebut dapat menjadi bekal peningkatan mutu di Universitas lampung apabila para pimpinan menindak lanjutinya secara baik. 6) Penciptaan kesadaran tentang pentingnya manajemen mutu untuk meningkatkan daya saing universitas, sehingga tujuan universitas menjadi benchmarking serta menjadi universitas yang berdaya saing dapat terpenuhi oleh Universitas Lampung. Maka dari itu dibutuhkan dukungan dan kerja sama yang kuat antara tim penjamin mutu dengan pimpinan Universitas. 


\section{DAFTAR RUJUKAN}

Direktorat Jenderal Pendidikan Tinggi, Hasil Implementasi Sistem penjaminan Mutu Internal di Perguruan Tinggi, 2008.

Huemert, Susan Harris, Evaluating Evaluators (An Evaluation of Education in Germany, Dissertation University of Oxford, 2009.

Juran \& Frank M. Gryna, Quality Planning and Analysis, (McGraww-Hill, Inc-1993).

Juran, Joseph M., A Blanton, Robert E. Hoogstool, Edward G. Schiling, Juran's Quality Hand book 5 editions, Mc Graw Hill, 2000.

Norris, Niggel, Dilemmas of Engagment : Evaluation and The New Public Management, JAI Press is an imprint of Elsevier, 2007.

Owen, John. M, Program Evaluation Foarms and Approach, Allen and Uwinn Press, 2006.

Patton, Michael Quinn., Qualitative Evaluation And Research Method, USA, Sage Publication Inc, 1990.

Stufflebeam, Danniel L. , George F. Madaus, Thomas Kellaghan, Evaluation Models :Viewpoints on Educational and Human Services Evaluation, Kluwer Academic Publisher, 2000. 